$551.510: 532.13$

\title{
Effect of Rotation on Convective Motion*
}

\author{
by \\ H. Arakawa \\ Meteorological Research Institute, Tokyo \\ (Received Octorber 20, 1960)
}

\begin{abstract}
A simple, preliminary experiment on the effect of rotation on convective motion has been carried out by the method of rotating cylinder convection. Two different regimes of motion, i.e., mushroom regime and tornado regime motion, have been observed. By increasing the rotation (decreasing the Rossby number), the approaching transition of the mushroom regime to the tornado regime motion has been shown by means of two series of photographs.
\end{abstract}

\section{Introduction}

Although the use of models in studying fluid motion is not a new technique, its application to large scale atmospheric phenomena has shown considerable progress in recent years. For example, a number of groups of hydrodynamic experiments have been successfully run almost continuously over several years since 1947 on problems of the medium- and large-scale hydrodynamic phenomena of the atmosphere by Dr. Fultz and his collaborators. A laboratory study of the primary ocean circulation was begun by voN Arx since 1950. Several works by Dr. LoNG and Dr. SuzukI (1953) represent an attempt to study experimentally the flow of an atmosphere with stratified fluids over mountain barriers. Experimental studies on free convection due to boundary sources have been carried out at Iowa Institute of Hydraulic Research. All these experimental studies have been summarized in several proceedings of the special symposium on fluid model experiments.

The present author intended to study experimentally the convective motion as well as the effect of rotation on convective motion in a quite primitive manner. This paper is partly devoted to experimental discussions on the mechanism of severe storms such as tornadoes and hurricanes.

\section{Experimental arrangements}

A cylinder made of glass, about $35 \mathrm{~cm}$ in diameter and about $36 \mathrm{~cm}$ in depth, is almost filled with a layer of water. SCORER and RONNE (1956) have released ready-made bubbles into a static tank of water and bubbles have been created by releasing a liquid denser than water. The denser fluid has been obtained by making a mud "slurry," whose tech-

\footnotetext{
* The research reported in this paper has been made possible through support and sponsorship extended by the National Hurricane Research Project, U.S. Weather Bureau. Their support is gratefully acknowledged.
} 


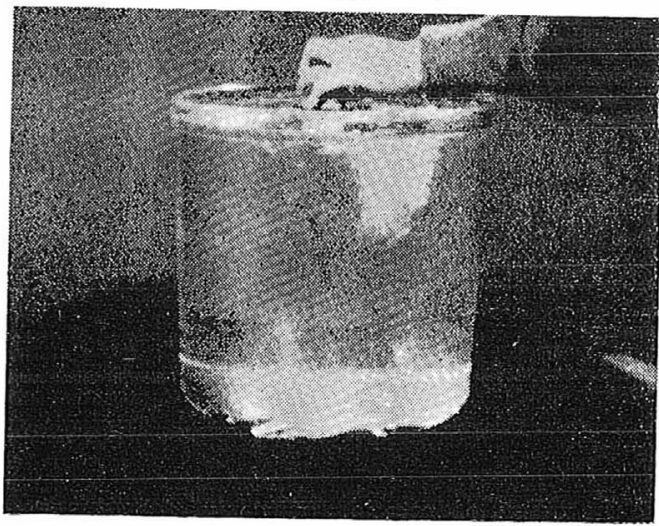

Fig. 1

nique was also employed in the present experiment.

To study experimentally the effect of rotation on the convective motion, the cylinder was mounted on a supporting frame on the rotating disc with variable speed. Observation and photographing of the convective motions were carried out directly. Photographic films were taken with standard cinema technique by Mr. M. SaIto (See Fig. 1).

\section{Convection bubbles in a static tank of water}

In the case of convection bubbles in a static tank it is absolutely the same as reported by SCORER and RONNE (1956). Five pictures of a bubble in succession after release are shown in Figs. $4(\mathrm{a}-\mathrm{e})$. We can see a welldeveloped mushroom regime motion in the course of convective motion. Mixing takes place between the liquid elements denser than water and their surroundings, and convective motions are finally damped out and are eroded.

Fig. 2. Five consecutive pictures of bubble after release show mushroom regime motion.
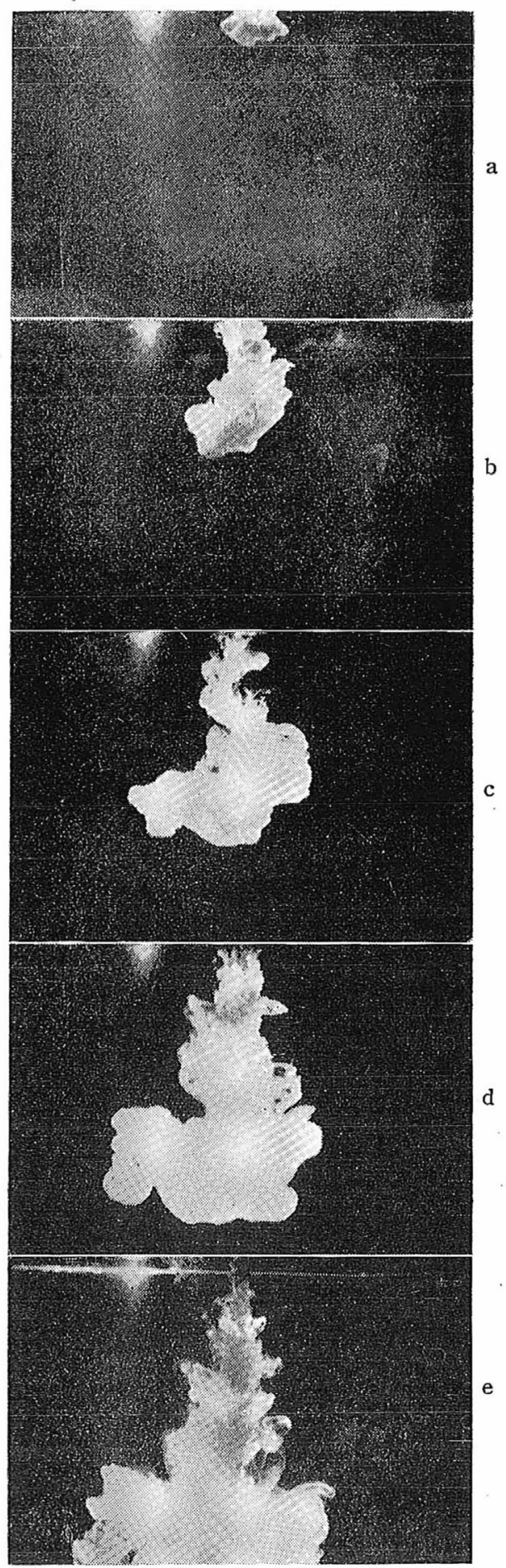


\section{Rotating cylinder convection:}

\section{Mushroom regime motion with low speed rotation}

Under suitable conditions, if the cylinder is rotated uniformly at a relatively low speed, say 14 revolutions per minute, the convective motion becomes more and more irregular and obscure, and makes an impression of rather turbulent flow. No theory at present can predict this type of irregular motion, concerning which any further theory must be more or less descriptive. Convection pattern after release is still of mushroom regime motion provided the speed of rotation remains sufficiently small.

It is evident that more mixing takes place between the buoyant elements and surroundings than in the case of a static tank of water. Figs. 3a-3e are shown to illustrate a mushroom regime motion with low speed rotation.

The most important type of characteristic parameter for the meteorological interpretation of such experiments is the RossBy number, which will be discussed in the next paragraph to explain two radically different regimes of motion.

\section{Tornado regime motion with high speed rotation}

If the cylinder is rotated uniformly at a higher speed, say 42 revolutions per minute, convective patterns make a sudden change from a mushroom regime to a tornado regime motion. The rotating pattern of bubbles after release becomes more narrow and systematic as shown in Figs. 4 (a-e).

The most powerful tool of experimenters on the fluid system is dimensional analysis.

Fig. 3. Mushroom regime motion with low speed rotation after release. Speed of rotation is about 14 revolutions per minute.

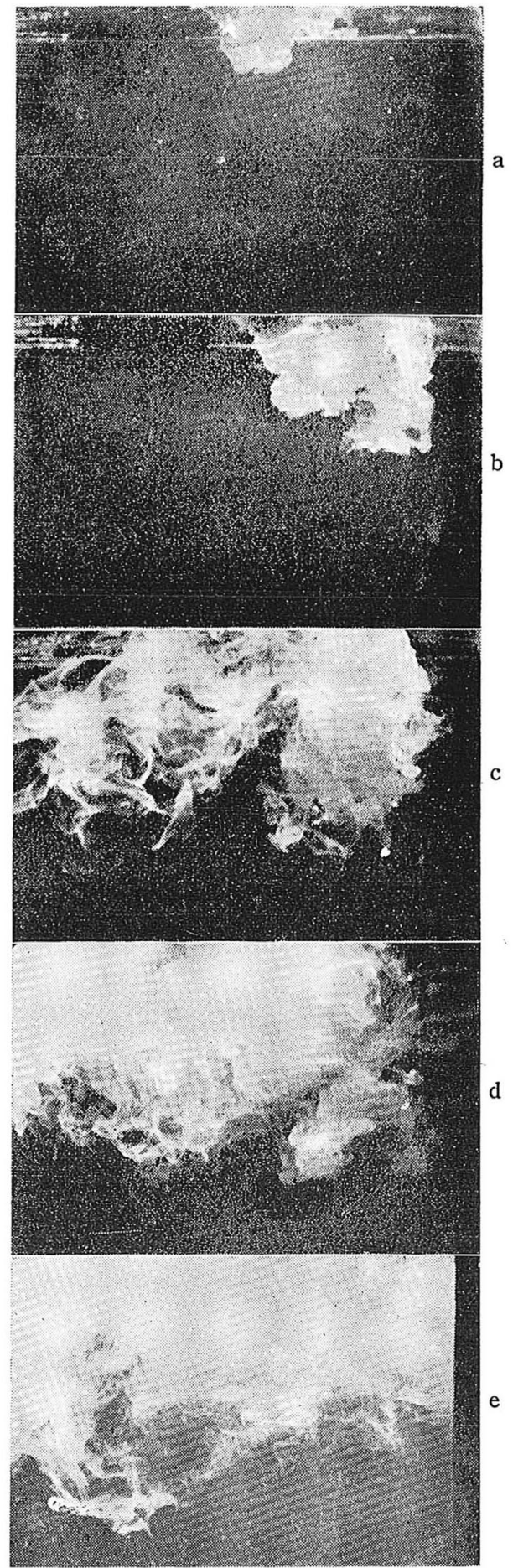


A quantitative form appropriate to the discussion of the rotating two-liquid experiments referred to above might be called a MARGULEAN form of the RossBy number

$$
R=\frac{g S \cdot \Delta \rho}{2 \Omega \rho_{0} \cdot A \Omega}
$$

where $g$ is the acceleration of gravity, $\rho_{o}$ is a mean density, $\Delta \rho$ is the density difference between the two liquids, $\Omega$ is the basic rotation, $A$ is a suitable length parameter, and $S$ is a representative slope of the interface. In practice it is usually more convenient to adapt $A$ as a definite quantity, normally a radius.

Many experimental results shown by Dr. Fultz (1953) show that a series of radically different regimes of convective motions occurs across the Rossby number values. By increasing the speed of rotation (decreasing $R$ ), the approaching transition from a mushroom regime to a tornado regime motion can befound as shown in Figs. $3(\mathrm{a}-\mathrm{e})$ and Figs. $4(\mathrm{a}-\mathrm{e})$.

Understanding of the problem of a transition from a normal mushroom regime to a tornado regime motion seems to be very important in physical meteorology, and studies along this line will be continued by our collaborators.

Acknowledgements ——When the present author visited M.I.T. in Massachusetts, U.S.A., a valuable stimulus has been given by Prof. V.P. STARr, who is now writing a series of papers on the effect of rotation on convective motion, to whom the author's hearty thanks are extended. Thanks are also due Mr.M. SAITo for valuable help in taking films of the convective motion in this study.

Fig. 4 Tornado regime motion with high speed rotation after release. Speed of rotation is about 42 revolutions per minute.

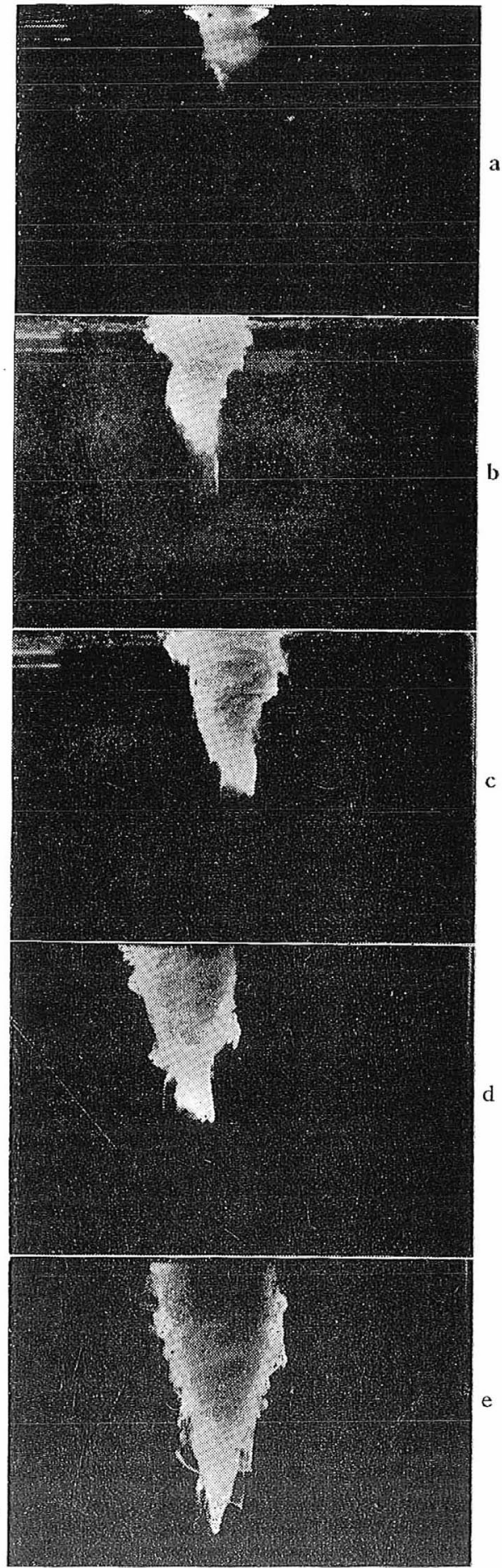




\section{References}

Fultz, D., 1953: A study of certain thermally and mechanically driven systems of meteorological interest, in Fluid models in geophysics, 27-63.

Fuldz D., and Colmaborators, 1959: Studies of thermal convection in a rotating cylinder with some implications for large-scale atmospheric motions, Meteorological Monographs, 4, No. 21, p. 104.

LoNG, R. R. Ed., 1953: Fluid models in geophysics, Washington D.C., pp. 162.

Scorer R.S., and Ronve, C. 1956: Experiments with convection bubbles, Weather, London, 11, $151-154$.

\section{対流に及ぼす回転の影響}

\section{荒 川秀 俊}

密度のや〉大きな浔水を水槽中にたらして刘流を扤こすと きのこ型の雲 (倒立) に似た形になる もし も水槽を回転すると回転の速度が小さいらちは 刘流は乱れを抗こしながらもきのこ型にとら゙まるし かし回転の速度がある限度より大きくなると 著者がトルネード型と呼んだ全く異質的な対流になるこ の二種の異質的な対流は 気像学的に大きな意味があると考えられる 